Baki Çiçek*, Merve Çağlı, Remziye Tülek and Ali Teke

\title{
Synthesis and optical characterization of bipod carbazole derivatives
}

https://doi.org/10.1515/hc-2020-0111

Received May 23, 2019; accepted July 17, 2020.

Abstract: In this study, some new biscarbazole derivatives were synthesized for the purpose of being used in OLED technologies and related areas. The following compounds: $\quad$ 1,2-bis(2-(3,6-diphenyl-9H-carbazole-9-yl) ethoxy)ethane (C-1), bis[2-(2-(3,6- diphenyl-9H-carbazole9-yl) ethoxy)etyl]ether (C-2), bis[2-(2-(3,6-di(naphthalene1-yl)-9H-carbazol-9-yl)ethoxy)etyl]ether (C-3) and bis [2-(2-(3,6-di(naphthalene-2-yl)-9H-carbazol-9-yl)ethoxy) ethyl]ether (C-4) were synthesized by Suzuki-Miyaura Cross Coupling reactions. The structural properties of the synthesized compounds were characterized by FT-IR, 1H-NMR, 13C-NMR, and LC-MS. The maximum product yields of $81.6 \%$ were obtained for C-4 biscarbazole derivatives. The optical properties were studied using UV-visible and temperature/excitation power density dependent photoluminescence (PL) techniques. The emissions were observed at green and yellow-red color spectral bands. By applying Gaussian fitting to the measured spectra, the superposition of the broad peaks was deconvoluted into two peaks. The origin of emissions was attributed to $\pi-\pi^{\star}$ transition in aromatic compounds caused by intramolecular charge transfer from host carbazole to these compounds.

Keywords: Bipod Carbazole, Suzuki-Miyaura Cross Coupling, Optical Characterization, Photoluminescence, OLED

\footnotetext{
*Corresponding author: Baki Çiçek, Chemistry Department, Faculty of Arts and Sciences, Balıkesir University, Balıkesir E-mail:Turkeybcicek@balikesir.edu.tr; mervecagli@live.com Merve Çağlı, Chemistry Department, Faculty of Arts and Sciences, Balıkesir University, Balıkesir E-mail:Turkeybcicek@balikesir.edu.tr; mervecagli@live.com Remziye Tülek and Ali Teke, Physics Department, Faculty of Arts and Sciences, Balıkesir University, Balıkesir

E-mail:Turkey baran@balikesir.edu.tr; ateke@balikesir.edu.tr
}

\section{List of abbreviations}

$\begin{array}{lll}\text { OLED } & : & \text { Organic Light Emitting Diodes } \\ \text { FT-IR } & : & \text { FourierTransform Infrared Spectroscopy } \\ { }^{1} \mathrm{H}-\mathrm{NMR} & : & \text { Proton Nuclear Magnetic Resonance } \\ { }^{13} \mathrm{C}-\mathrm{NMR} & : & \text { Carbon Nuclear Magnetic Resonance } \\ \text { TBAI } & : & \text { Tetrabutylammonium iodide } \\ \delta & : & \text { Chemical Shift } \\ \mathrm{M}^{+} & : & \text {Molecular Ion Peak }\end{array}$

\section{Introduction}

Biscarbazoles as luminescent materials which include two aromatic heterocyclic organic compounds have been designed and synthesized for exploring some applications. These include organic light-emitting diodes (OLEDs) [1-3], organic photovoltaic and electronic devices [4-10], studying biochemical activities [11-18] and fundamental points of view $[19,20]$. Such molecules are especially suited to implementation in OLED technologies because of the electron donation of nitrogen on the carbazole ring. The efficient charge transfer from host carbazoles to connected molecules is provided by a strong $\pi$-electron conjugation. Carbazoles have been used as host matrices in highly efficient blue, green, or red electro-phosphorescent devices [6-8,16,21]. They also have good thermal properties and structural stability, allowing them to be used as a hole transport layer in OLED technology [22-30]. Carbazole/thioxanthene-S, S'-dioxide (EBCz-ThX) bipolar molecules synthesized by electron accepting and electron donating groups with a solvent-free green chemistry method were presented as blue phosphorescent light emitting devices [31]. A green light with a peak maximum at $550 \mathrm{~nm}$ under an applied external voltage was reported from a diode based on 2,4-dicarbazolylquinoline [32]. Multicarbazole derivatives with twisted and zigzag-shape structures were synthesized and used as sensitizers for dye-sensitized solar cells [33]. 
To identify the potential use of newly synthesized molecules in various applications, their photophysical and electrochemical properties need to be investigated. As an example, Slodek et al. reported a strong dependence of optical properties on the number of carbazole units and length of alkyl chain on said carbazole units in the molecule, as well as the position of substitution of carbazole for a donor-acceptor (D-A) system based on 2,4-dicarbazolyl-substituted quinolines. The lowtemperature PL spectra were characterized by the spinallowed fluorescence $(400 \mathrm{~nm})$ and spin-forbidden phosphorescence (490-527 $\mathrm{nm}$ ) bands [34]. The synthesis and optical characterization of a salicylaldimine difluoroboron complex with tert-butyl group was carried out by Zhang and co-workers. The maximal emission peak of the synthesized compound in THF at $514 \mathrm{~nm}$ was ascribed to intramolecular charge transfer (ICT) emission. The peak positions of fluorescence emissions were blue and red-shifted to 506 and $522 \mathrm{~nm}$ for crystal structure and ground powder respectively [32]. Complex yellow (centered at $\sim 574 \mathrm{~nm}$ ) and red (centered at $~ 704$ $\mathrm{nm}$ ) colors were observed, with the relative intensities dependent on functional groups in PL spectra, for novel carbazole derivatives synthesized using a condensation reaction between carbazole amines and aromatic aldehydes [35].

Although carbazoles have been synthesized with substitutions in all positions (on benzene rings and nitrogen) [36], substitutions on 3- and 6- positions are very common [30, 32-35]. Various methods with several steps have been used for substitution on the aromatic rings [36, 39]. The most common and successfully used method is the Suzuki-Miyaura Cross Coupling Reaction [42-48]. The selection of groups expected to substitute on the desired positions is very important due to their crucial effect on the optical properties of the final product.

This study includes the synthesis and characterization of novel biscarbazole derivatives which were obtained by connection of two carbazole molecules through their nitrogen positions and substitution of phenyl, $\alpha$-naphthyl and $\beta$-naphthyl on their 3- and 6-positions using the Suzuki-Miyaura Cross Coupling Reaction. The formation of synthesized molecules was determined by infrared spectroscopy (FT-IR), nuclear magnetic resonance spectroscopy (NMR), mass spectrometry (MS) and microanalysis methods. Their optical properties were studied using UV-Vis spectroscopy and temperature/excitation power density dependent photoluminescence (PL).

\section{Materials and methods}

\section{General}

All starting materials were purchased from Merck, Sigma-Aldrich and Fluka Co., and were used after further analytical purifications using silica gel column chromatography. FT-IR spectra were taken using Perkin Elmer BX2 FTIR Spectrometer. Both ${ }^{1} \mathrm{H}-\mathrm{NMR}(400 \mathrm{MHz})$ and ${ }^{13} \mathrm{C}-\mathrm{NMR}(100 \mathrm{MHz})$ spectra were obtained in $\mathrm{CDCl}_{3}$ using an Agilent Tech. 400 NMR Spectrometer. LC-MS spectra were recorded on an Agilent Technologies-1260 Infinity (LC) 6130 Quadropole (MS) Mass Spectrometer using acetonitrile as the solvent. Microanalyses were performed with a Thermo Scientific Flash 2000 elemental analyzer. The absorption spectra were recorded using a Perkin-Elmer Lambda 25 UV-Vis Spectrometer. The temperature and excitation power density dependent photoluminescence measurements were performed in the temperature range of $20-300 \mathrm{~K}$ and excitation power densities between $2.6-330 \mathrm{~mW} / \mathrm{cm}^{2}$. A frequency tripled Nd:YLFQ-switched pulse laser at 349 $\mathrm{nm}$ was used for the excitation. The luminescence was collected by suitable lenses and then dispersed with a $500 \mathrm{~mm}$ spectrometer using 1200 line/mm grating and detected by Intensified Charge Coupled Device (ICCD) camera.

\section{Experimental}

\section{Synthesis of 3,6-dibromocarbazole (B)}

Carbazole (A) ( $5 \mathrm{mmol}, 0.835 \mathrm{~g}$ ) was firstly dissolved in $100 \mathrm{ml}$ of dichloromethane. $\mathrm{SiO}_{2}(20 \mathrm{~g})$ was then added and stirred. A solution which contained NBS $(10 \mathrm{mmol}$, $1.78 \mathrm{~g}$ ) dissolved in $150 \mathrm{ml}$ of dichloromethane was added dropwise to the carbazole mixture, and was continuously stirred at room temperature for 24 hours in a dark environment [45]. The entire mixture was then filtered and the residue was washed with dichloromethane $(3 \times 30 \mathrm{ml})$. The combined organic fractions were rinsed with water $(200 \mathrm{ml})$ and, after the phases were separated, the organic layer was collected. The solvent was evaporated after which a light green powder was obtained (1.176 g, yield: $72 \%)$. FT-IR $(y \mathrm{~cm}-1)$ : 3403 (N-H stretch), 3071 (aromatic C-H stretch), 1598 (aromatic $\mathrm{C}=\mathrm{C}$ stretch), 1459 (carbazole ring stretch), 1127 (C-N bend), 802 (C-Br bend), 739 and 686 (aromatic C-H out-of-plane bend) 


\section{General Procedure-I for synthesis of bromine substituted biscarbazoles}

3,6-dibromocarbazole (B) (2.0 equivalent), 1,2-bis(2chloroethoxy)ethane (1.0 equivalent), TBAI and 50\% $\mathrm{NaOH}$ solution $(10 \mathrm{ml})$ were added in $100 \mathrm{ml}$ flask and refluxed while it was stirring at $78^{\circ} \mathrm{C}$ for 48 hours [49]. After the reaction was complete, the mixture was cooled down to room temperature. The mixture was then filtered with dichloromethane $(3 \times 30 \mathrm{ml})$ and washed in water $(200 \mathrm{ml})$. Organic phase was obtained after separating the layers and drying over $\mathrm{Na}_{2} \mathrm{SO}_{4}$. The solution was evaporated and the oily solid product was obtained by recrystallizing from a mixture of chloroform $/ n$-hexane (1:1) (see Figure 1).

\section{Synthesis of 1,2-bis(2-(3,6-dibromo-9H-carbazole-9-yl) ethoxy)ethane (C-a1)}

Synthesized using General Procedure-I with 3,6-dibromocarbazole (3 mmol, $0.970 \mathrm{~g})$, 1,2-bis(2chloroethoxy)ethane (1.5 mmol, $0.24 \mathrm{ml})$, TBAI $(0.36 \mathrm{~g})$ to give the oily solid product $(0.585 \mathrm{~g}, 46.7 \%)$. FT-IR $\left(\mathrm{y} \mathrm{cm}^{-1}\right)$ : 3071 (Aromatic C-H stretch), 2956 and 2871 (symmetric and asymmetric aliphatic C-H stretch), 1624-1546 (carbazole ring stretch), 1471 (asymmetric aliphatic C-H bend), 1435 (carbazole ring stretch), 1290 (symmetric aliphatic C-H bend), 1108 (C-O-C asymmetric bend), 1058 (N-C bend), 1031 (C-O-C symmetric bend), 1017 (aliphatic C-H out-ofplane bending), 797 (C-Br bend), 750 and 648 (Aromatic C-H out-of-plane symmetric bending).

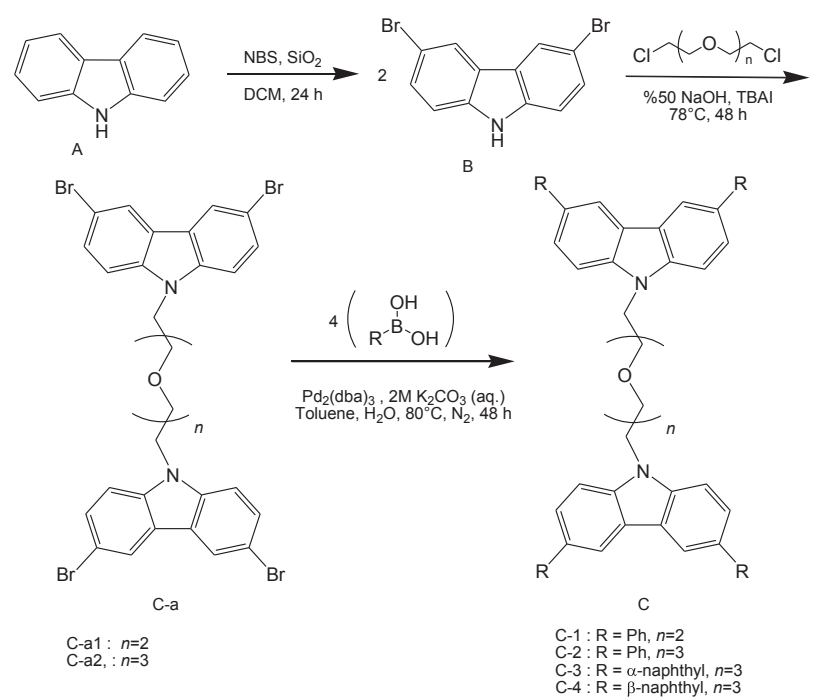

Figure 1 Synthesis of the original bipod carbazole derivatives ( $\mathbf{C}-1$, C-2, C-3, C-4)

\section{Synthesis of Bis[2-(2-(3,6-dibromo-9H-carbazole-9-yl) ethoxy)etyl]ether ( $C-a 2)$}

Synthesized using General Procedure-I with 3,6-dibromocarbazole (2.8 mmol, $0.91 \mathrm{~g})$, bis[2-(2-chloroethoxy)ethyl] ether $(1.38 \mathrm{mmol}, 0.27 \mathrm{ml})$, TBAI $(0.50 \mathrm{~g})$ to give the oily solid product $(0.424 \mathrm{~g}, 37.5 \%)$. FT-IR $\left(\mathrm{y} \mathrm{cm}^{-1}\right)$ : 3062 (aromatic C-H stretch), 2956 and 2871 (aliphatic asymmetric and symmetric stretch), 1471 (aliphatic asymmetric C-H bend), 1435 (carbazole ring stretch), 1290 (aliphatic C-H, in-plane, symmetric bending), 1108 (C-O-C asymmetric bend), 1057 (N-C bend), 1033 (C-O-C symmetric bend), 1017 (C-H, aliphatic out-of-plane bending), 798 (C-Br bend), 737 and 648 (aromatic C-H out-of-plane, symmetric bending).

\section{General Procedure-II for synthesis of bipod carbazole derivatives}

Brominated carbazoles ( $\boldsymbol{C}$ - $\boldsymbol{a} \mathbf{1}$ or $\boldsymbol{C}$ - $\boldsymbol{a 2}$ ) (3.33 equivalent), $\mathrm{PhB}(\mathrm{OH})_{2}$ (13.33 equivalent) and $\mathrm{Pd}_{2}(\mathrm{dba})_{3} \quad(1.0$ equivalent) were placed in $100 \mathrm{ml}$ flask. $\mathrm{K}_{2} \mathrm{CO}_{3}$ (aq., 2M), toluene and two drops of Aliquot 336 were quickly added. The mixture degassed with nitrogen was stirred at $80^{\circ} \mathrm{C}$ for 48 hours in a nitrogen atmosphere. The reaction was complete and allowed to cool to room temperature. It was then filtered in dichloromethane $(3 \times 30 \mathrm{ml})$ and washed with water $(200 \mathrm{ml})$. Organic phase was obtained after separating the layers and drying over $\mathrm{Na}_{2} \mathrm{SO}_{4}$. The solution was evaporated and recrystallized from ethanol.

\section{Synthesis of 1,2-bis(2-(3,6-diphenyl-9H-carbazole-9-yl) ethoxy)ethane $(C-1)$}

C-1 was obtained from 1,2-bis(2-(3,6-dibromo-9Hcarbazole-9-yl) ethoxy)ethane (C-a1) $(0.2 \mathrm{mmol}, 0.15 \mathrm{~g})$, $\mathrm{PhB}(\mathrm{OH})_{2}(0.8 \mathrm{mmol}, 0.098 \mathrm{~g})$ and $\mathrm{Pd}_{2}(\mathrm{dba})_{3}(0.06$ mmol, $0.055 \mathrm{~g}$ ) and $\mathrm{K}_{2} \mathrm{CO}_{3}$ (aq., 2M, $3 \mathrm{ml}$ ), toluene (6 ml) following the General Procedure-II. The yellow, slightly oily solid product was achieved by recrystallization from ethanol $(0.020 \mathrm{~g}, 13.5 \%)$. FT-IR $\left(\mathrm{y} \mathrm{cm}^{-1}\right): 3058$ and 3024 (aromatic C-H stretch), 2926 and 2871 (C-H, symmetric and asymmetric stretch), 1599 (Aromatic $\mathrm{C}=\mathrm{C}$ stretch), 1470 (C-H, aliphatic, in-plane, asymmetric bend), 1449 (carbazole ring stretch), 1340 (aliphatic C-H bend, in-plane, symmetric), 1135 (C-O-C asymmetric bend), 1111 (aliphatic C-H, out-of-plane bending), 1067 (C-N bend), 1018 (C-O-C symmetric bend), 748 and 702 
(aromatic C-H, out-of-plane, symmetric bending). ${ }^{1} \mathrm{H}$ NMR $\left(\mathrm{CDCl}_{3}, \delta, \mathrm{ppm}\right): 3.475(2 \mathrm{H}, \mathrm{s}), 3.832(2 \mathrm{H}, \mathrm{t})$, $4.429(2 \mathrm{H}, \mathrm{t}), 7.526(1 \mathrm{H}, \mathrm{d}), 8.107(1 \mathrm{H}, \mathrm{m}), 7.612(1 \mathrm{H}, \mathrm{m})$, $7.612(1 \mathrm{H}, \mathrm{d}), 7.406(1 \mathrm{H}, \mathrm{s}), 7,412(1 \mathrm{H}, \mathrm{d}), 7.390(1 \mathrm{H}, \mathrm{s})$. ${ }^{13} \mathrm{C}$ NMR $\left(\mathrm{CDCl}_{3}, \delta\right.$, ppm): 69.323, 70.527, 58.602, 130.514, 123.191-110.632, 143.323, 139.551, 128.380, 128.959, 129.081. Anal. Calc. for $\mathrm{C}_{54} \mathrm{H}_{44} \mathrm{~N}_{2} \mathrm{O}_{2}(\mathrm{MW}=752.34): \mathrm{C}, 86.14 ; \mathrm{H}, 5.89$; $\mathrm{N}$, 3.72. Found: C, $86.00 ; \mathrm{H}, 5.81 ; \mathrm{N}, 3.77 \%$. LC-MS $(\mathrm{m} / \mathrm{z})$ : $753.30\left(\mathrm{M}^{+}, \mathrm{CH}_{3} \mathrm{CN}\right.$, Error $\left.\%=0.128\right)$.

\section{Synthesis of Bis[2-(2-(3,6-diphenyl-9H-carbazole-9-yl) ethoxy)etyl]ether( $C-2)$}

C-2 was obtained from bis[2-(2-(3,6-dibromo-9H-carbazole9-yl)ethoxy)etyl]ether (C-a2) (0.2 mmol, $0.16 \mathrm{~g}), \mathrm{PhB}(\mathrm{OH})_{2}$ $(0.8 \mathrm{mmol}, 0.098 \mathrm{~g})$ and $\mathrm{Pd}_{2}(\mathrm{dba})_{3}(0.06 \mathrm{mmol}, 0.055 \mathrm{~g})$ and $\mathrm{K}_{2} \mathrm{CO}_{3}$ (aq., $\left.2 \mathrm{M}, 3 \mathrm{ml}\right)$, toluene $(6 \mathrm{ml})$ following the General Procedure-II. The yellow-green, slightly oily solid was recrystallized from ethanol $(0.127 \mathrm{~g}, 80.3 \%)$. FT-IR $\left(\mathrm{ycm}^{-1}\right)$ :3055(aromatic C-Hstretch), 2924and2855(aliphatic $\mathrm{C}-\mathrm{H}$, symmetric and asymmetric stretch), 1596 (aromatic $\mathrm{C}=\mathrm{C}$ stretch), 1470 (aliphatic C-H bend, asymmetric), 1448 (carbazole ring stretch), 1343 (aliphatic C-H bend, symmetric), 1139 (C-O-C asymmetric bend), 1112 (aliphatic C-H bend, out-of-plane), 1055 (C-N bend), 1018 (C-O-C symmetric bend), 740 and 701 (aromatic $\mathrm{C}-\mathrm{H}$ bend, out-ofplane, symmetric). ${ }^{1} \mathrm{H}$ NMR $\left(\mathrm{CDCl}_{3}, \delta, \mathrm{ppm}\right): 3.472(4 \mathrm{H}, \mathrm{s})$, $3.810(2 \mathrm{H}, \mathrm{t}), 4.291(2 \mathrm{H}, \mathrm{t}), 7.619(1 \mathrm{H}, \mathrm{d}), 8.074(1 \mathrm{H}, \mathrm{d}), 8.089$ $8.106(1 \mathrm{H}, \mathrm{d}), 8.040(1 \mathrm{H}, \mathrm{d}), 7.601(1 \mathrm{H}, \mathrm{s}), 7.401(1 \mathrm{H}, \mathrm{s})$, 7.417 (1H, d), 7.333 (1H, m). ${ }^{13} \mathrm{C}$ NMR ( $\left.\mathrm{CDCl}_{3}, 8, \mathrm{ppm}\right):$ 70.535, 69.301, 70.901, 60.644, 131.885, 110.831, 123.434143 .323 , 123.945, 123.023, 139.521, 128.395, 128.974, 127.237. Anal. Calc. for $\mathrm{C}_{56} \mathrm{H}_{48} \mathrm{~N}_{2} \mathrm{O}_{3}$ (MW=796.37): C, 84.39; $\mathrm{H}, 6.07 ; \mathrm{N}, 3.51$. Found: C, 84.36; H, 6.01; N, 3.55\%. LC-MS (m/z): 796.40 $\left(\mathrm{M}^{+}, \mathrm{CH}_{3} \mathrm{CN}\right.$, Error \% $\left.=0.004\right)$.

\section{Synthesis of Bis[2-(2-(3,6-di(naphthalene-1-yl)-9H- carbazol-9-yl)ethoxy)etyl]ether( $C-3)$}

C-3 was obtained from bis[2-(2-(3,6-dibromo-9H-carbazole9-yl)ethoxy)etyl]ether (C-a2) (0.04 mmol, $0.032 \mathrm{~g})$, naphthalene-1-boronic acid (0.16 mmol, $0.028 \mathrm{~g})$ and $\operatorname{Pd}_{2}(\mathrm{dba})_{3}(0.0012 \mathrm{mmol}, 0.001 \mathrm{~g})$ were placed in a $100 \mathrm{ml}$ flask, then quickly $\mathrm{K}_{2} \mathrm{CO}_{3}$ (aq., $2 \mathrm{M}, 6 \mathrm{ml}$ ), toluene $(12 \mathrm{ml})$ following the General Procedure-II. The light-brown, slightly oily solid was recrystallized from ethanol $(0.024 \mathrm{~g}$, 61.3\%). FT-IR $\left(\mathrm{y} \mathrm{cm}^{-1}\right)$ : 3062 and 3026 (aromatic C-H stretch), 2923 and 2854 (aliphatic C-H stretch, asymmetric and symmetric), 1656, 1579 and 1496 (aromatic C=C stretch, naphthalene), 1600 (carbazole $\mathrm{C}=\mathrm{C}$ stretch), 1467 (aliphatic C-H bend, asymmetric), 1454 (carbazole ring stretch), 1291 (aliphatic C-H bend, symmetric), 1120 (C-O-C asymmetric bend), 1075 (aliphatic C-H bend, out-of-plane), 1057 (C-N bend), 1030 (C-O-C symmetric bend), 801 and 780 (aromatic symmetric $\mathrm{C}-\mathrm{H}$ bending on $\alpha$-substituted naphthalene, out-of-plane), 757 and 698 (aromatic symmetric carbazole bend, out-of-plane). ${ }^{1} \mathrm{H}$ $\operatorname{NMR}\left(\mathrm{CDCl}_{3,} \delta, \mathrm{ppm}\right): 3.388(4 \mathrm{H}, \mathrm{s}), 3.498(2 \mathrm{H}, \mathrm{t}), 3.635(2 \mathrm{H}, \mathrm{t})$, $7.262(1 \mathrm{H}, \mathrm{d}), 7.590(1 \mathrm{H}, \mathrm{d}), 7.608(1 \mathrm{H}, \mathrm{d}), 7.539(1 \mathrm{H}, \mathrm{d})$, $7.281(1 \mathrm{H}, \mathrm{s}), 8.060(1 \mathrm{H}, \mathrm{m}), 7.222-7.135(2 \mathrm{H}, \mathrm{m}), 7.467(1 \mathrm{H}$, m), $7.498(1 \mathrm{H}, \mathrm{m}), 7.377(1 \mathrm{H}, \mathrm{d}), 7.940(1 \mathrm{H}, \mathrm{d}) .{ }^{13} \mathrm{C}$ NMR $\left(\mathrm{CDCl}_{3}, \delta, \mathrm{ppm}\right)$ : 74.010-72.125, 61.406, 133.150, 125.332, 125.759, 141.253, 126.505, 125.926, 138.408, 132.807, 128.106, 127.854, 133.485, 128.185, 127.786. Anal. Calc. for $\mathrm{C}_{72} \mathrm{H}_{56} \mathrm{~N}_{2} \mathrm{O}_{3}$ (MW=996.43): C, 86.72; H, 5.66; N, 2.81. Found: C, 86.68; $\mathrm{H}, 5.60 ; \mathrm{N}, 2.90 . \%$. LC-MS $(\mathrm{m} / z): 996.43\left(\mathrm{M}^{+}, \mathrm{CH}_{3} \mathrm{CN}\right.$, Error \% $=0.003)$.

\section{Synthesis of Bis[2-(2-(3,6-di(naphthalene-2-yl)-9H- carbazol-9-yl)ethoxy)ethyl]ether( $C-4)$}

C-4 was obtained from bis[2-(2-(3,6-dibromo-9H-carbazole-9-yl)ethoxy)etyl]ether (C-a2) $(0.06 \mathrm{mmol}, 0.048 \mathrm{~g})$, 2-naphthylboronic acid $(0.24 \mathrm{mmol}, 0.041 \mathrm{~g})$ and $\mathrm{Pd}_{2}(\mathrm{dba})_{3}(0.0018 \mathrm{mmol}, 0.0016 \mathrm{~g})$ were placed in a $100 \mathrm{ml}$ flask, then quickly $\mathrm{K}_{2} \mathrm{CO}_{3}$ (aq., $2 \mathrm{M}, 9 \mathrm{ml}$ ), toluene $(18 \mathrm{ml})$ following the General Procedure-II. The lightbrown, slightly oily solid was recrystallized from ethanol $(0.048 \mathrm{~g}, 81.6 \%)$. FT-IR $\left(\mathrm{y} \mathrm{cm}^{-1}\right)$ : 3054 and 3022 (aromatic C-H stretch), 2923 and 2854 (symmetric and asymmetric aliphatic C-H stretch), 1624, 1569 and 1494 (aromatic $\mathrm{C}=\mathrm{C}$ stretch, naphthalene), 1594 (carbazole $\mathrm{C}=\mathrm{C}$ stretch), 1467 (aliphatic $\mathrm{C}-\mathrm{H}$ bend, asymmetric), 1454 (cbz ring stretch), 1290 (C-H aliphatic, in-plane, symmetric), 1131 (C-O-C asymmetric bend), 1076 (aliphatic C-H bend, out-of-plane), 1031 (C-O-C symmetric stretch), 811 and 737 (aromatic symmetric $\mathrm{C}-\mathrm{H}$ bend on $\beta$-substituted naphthalene, out-of-plane), 748 and 699 (aromatic symmetric C-H bend on carbazole benzene, out-of-plane,). ${ }^{1} \mathrm{H}$ NMR ( $\left.\mathrm{CDCl}_{3}, \delta, \mathrm{ppm}\right): 3.287(4 \mathrm{H}, \mathrm{s})$, $3.725(2 \mathrm{H}, \mathrm{t}), 4.379(2 \mathrm{H}, \mathrm{t}), 7.218(1 \mathrm{H}, \mathrm{d}), 7.927(1 \mathrm{H}, \mathrm{s})$, $7.900(1 \mathrm{H}, d), 8.122-8.059(1 \mathrm{H}, \mathrm{d}), 7.258(1 \mathrm{H}, \mathrm{s}), 7.514(2 \mathrm{H}$, m), $7.279(2 \mathrm{H}, \mathrm{s}), 7.952(1 \mathrm{H}, \mathrm{d}), 7.361(1 \mathrm{H}, \mathrm{d}) .{ }^{13} \mathrm{C} \mathrm{NMR}$ $\left(\mathrm{CDCl}_{3}, \delta, \mathrm{ppm}\right)$ : 70.548, 70.650, 125.332, 125.759, 61.434, $133.757,125.718,126.099,143.210,126.381,126.030$, $138.398,127.684,133.510,128.537,132.675,128.233$. Anal. Calc. for $\mathrm{C}_{72} \mathrm{H}_{56} \mathrm{~N}_{2} \mathrm{O}_{3}(\mathrm{MW}=996.43)$ : C, 86.72; $\mathrm{H}, 5.66$; N, 2.81. Found: C, 86.65; H, 5.63; N, $2.85 \%$. LC-MS $(\mathrm{m} / z)$ : $996.43\left(\mathrm{M}^{+}, \mathrm{CH}_{3} \mathrm{CN}\right.$, Error \% = 0.003). 


\section{Results}

In this work 1,2-bis(2-(3,6-diphenyl-9H-carbazole-9-yl) ethoxy)ethane (C-1), bis[2-(2-(3,6- diphenyl-9H-carbazole9-yl) ethoxy)etyl]ether (C-2), bis[2-(2-(3,6-di(naphthalene1-yl)-9H-carbazol-9-yl)ethoxy)etyl]ether (C-3) and bis[2-(2-(3,6-di(naphthalene-2-yl)-9H-carbazol-9-yl) ethoxy)ethyl]ether (C-4) were synthesized. The syntheses of these compounds were started by brominating the 3and 6- position of the carbazole ring. During this process, $\mathrm{SiO}_{2}$ was used as an efficient-reusable catalyst [42]. Then, two molar equivalents of bromo carbazole were led to react with dichloroether derivatives via $\mathrm{S}_{\mathrm{N}} 2$ reaction. The oily solid product was obtained by recrystallizing the mixture of chloroform $/ n$-hexane (1:1). Finally, the bromines were replaced by phenyl boronic acid, $\alpha$-naphthyl boronic acid and $\beta$-naphthyl boronic acid moieties via the SuzukiMiyaura Cross Coupling Reaction. The oily solid products were re-crystallized from ethanol. The yields of C-1, C-2, C-3 and $\mathbf{C - 4}$ bipod carbazole derivatives were obtained as $13.5,80.3,61.3$ and $81.6 \%$, respectively.

In FT-IR spectra, the N-H stretch peak of secondary amines which is only seen in carbazole and 3,6-dibromocarbazole, disappeared due to the reaction between 3,6-dibromocarbazole and 1,2-bis(2chloroethoxy)ethane. Therefore, the $\mathrm{N}-\mathrm{H}$ stretch peak was not observed in FT-IR spectra of C-a1, a2, 1, 2, 3, and 4. The $\mathrm{C}-\mathrm{Br}$ stretch peak was observed in 3,6-dibromocarbazole, C-a1 and C-a2 but not in C-1, 2, 3, and 4. These results indicate that no $\mathrm{Br}$ atoms attached on carbazole were left. $\mathrm{Br}$ atoms were replaced by substitution of boron acid molecules via the SuzukiMiyaura Cross Coupling reaction. Symmetric and asymmetric peaks of aliphatic $\mathrm{C}-\mathrm{H}$ and $\mathrm{C}-\mathrm{O}-\mathrm{C}$ were observed in C-a1, a2, 1, 2, 3 and 4, but not in carbazole or 3,6-dibromocarbazole. This indicates the presence of ether and aliphatic groups. As a result, the syntheses of intermediate and final products were confirmed with FT-IR data.

The ${ }^{1} \mathrm{H}-\mathrm{NMR}$ and ${ }^{13} \mathrm{C}$-NMR spectra data also support successful synthesis of C-1, C-2, C-3 and C-4 (supplementary materials). For example, in ${ }^{1} \mathrm{H}-\mathrm{NMR}$ spectra of C-3 molecule, ether peaks labeled as 1, 2, and 3 were observed at $\delta 3.472-4.291 \mathrm{ppm}$ and aromatic peaks at $\delta$ 7.619-8.106 ppm (supplementary materials). In ${ }^{13} \mathrm{C}-\mathrm{NMR}$ spectra of the same molecule, ether peaks were observed at $\delta 60.644-70.901 \mathrm{ppm}$, and aromatic peaks at $\delta 110.831-$ $143.323 \mathrm{ppm}$ (supplementary materials).

The molecular ion peaks of $\mathbf{C}-\mathbf{1}, \mathbf{C}-\mathbf{2}, \mathbf{C}-\mathbf{3}$, and $\mathbf{C}-\mathbf{4}$ were obtained from LC-MS spectra taken in dichloromethane. The spectra contain peaks of molecular ions and other possible ions (supplementary materials). The results of microanalysis also support successful synthesis of compounds.

In UV-vis spectra, the absorption bands were observed in the range of $225-380 \mathrm{~nm}$ for all samples. This range is suitable for our PL measurement using $349 \mathrm{~nm}$ laser.

The PL spectra are shown in Figure 2 together with reference sample containing only carbazole for comparison. The reference sample has several relatively narrow peaks over the spectral range between 370 and $500 \mathrm{~nm}$ with the most intense peak situated at $420 \mathrm{~nm}$.

In the work done by Zhang et al. [32], three absorption peaks located at 294, 354 and $379 \mathrm{~nm}$ were observed for salicylaldimine difluoroboron complex with tert-butyl group. They were attributed to carbazole, $\pi-\pi^{\star}$ and intramolecular charge transfer (ICT) transitions respectively. The emission peak of the synthesized compound in THF mixure present at $514 \mathrm{~nm}$ was ascribed to ICT emission. The peak positions of fluorescence emissions were blue and red-shifted to 506 and $522 \mathrm{~nm}$ for crystal structure and ground powder respectively. The optical properties of two 2,4-difluorenylquinoline derivatives with different lengths of alkyl chain at the fluorene unit (one with methyl and other with octyl chain) of donor-acceptor (D-A) type were reported by Slodek et al [50]. They observed bright emission in the blue spectral region at $406 \mathrm{~nm}$, whereas the replacement of fluorine with carbazole unit resulted in a bathochromic shift of peak wavelength with emission bands at 425 and $530 \mathrm{~nm}$.

Due to stronger $\pi$-conjugation and efficient intramolecular charge transfer from carbazole to aromatic

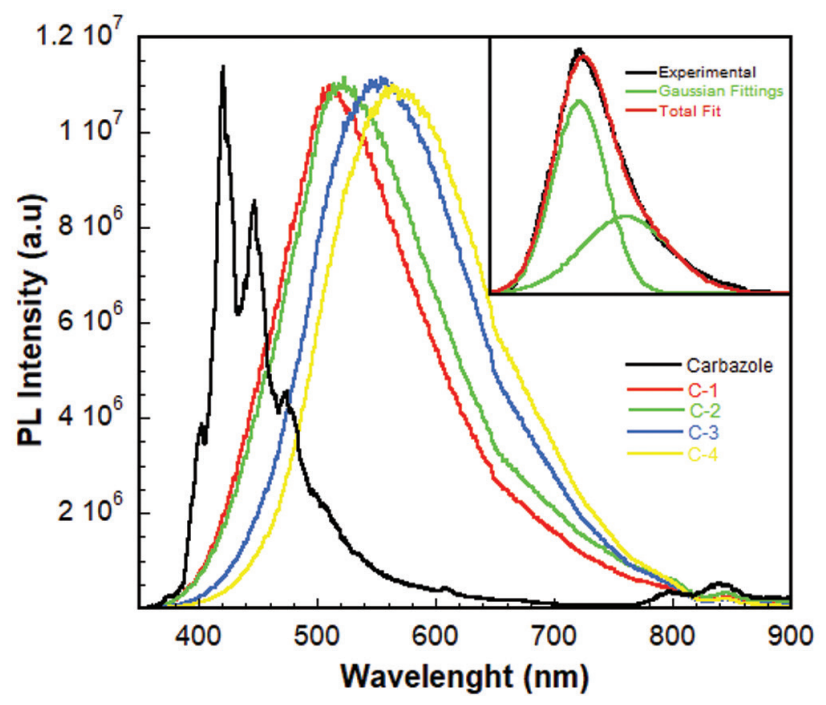

Figure 2 PL spectra for all samples at room temperature 
compounds, the PL spectra of $\mathbf{C - 1}, \mathbf{C}-\mathbf{2}, \mathbf{C}-\mathbf{3}$ and $\mathbf{C}-\mathbf{4}$ depict completely different character compared to carbazole. As first seen, all spectra were dominated with a broad peak at about $~ 513,523,553,565 \mathrm{~nm}$ for samples C-1, C-2, C-3 and C-4, respectively. However, these peaks were decomposed into two peaks using Gauss fitting as shown in the inset.

Figures 3 and 4 show temperature dependent PL peak positions (the one at high energy side of spectrum) and normalized integrated intensities deduced from the Gauss fitting to the experimental data. From figures, the peak wavelengths and integrated intensities are approximately temperature independent for $\mathbf{C}-\mathbf{1}$ and $\mathbf{C}-\mathbf{2}$. This is consistent with the spatial configuration of structures C-1 and $\mathbf{C}-\mathbf{2}$, where the most stable formation is expected at the anti-position of the carbazole and benzene rings. Within the temperature range studied in PL measurement, no changes are expected for both structures. On the other hand, for the samples (C-3 and $\mathbf{C}-\mathbf{4})$, in which the $\alpha$-naphthyl and $\beta$-naphthyl are attached to carbazole, the peak wavelengths and integrated intensities increase as the temperature increases. At low temperatures, the rotation around the sigma bond is weak and prefers to be at the most stable anti-position. As the temperature increases the rotation of the sigma bond is expected to increase. A resonance occurs when the electrons of $p$ orbital of carbazole that do not participate in hybridization and p orbital of naphthyl group come to the same parallel plane. This provides a complete resonance on the molecule that causes redshift in the peak wavelength positions and increases in integrated intensities

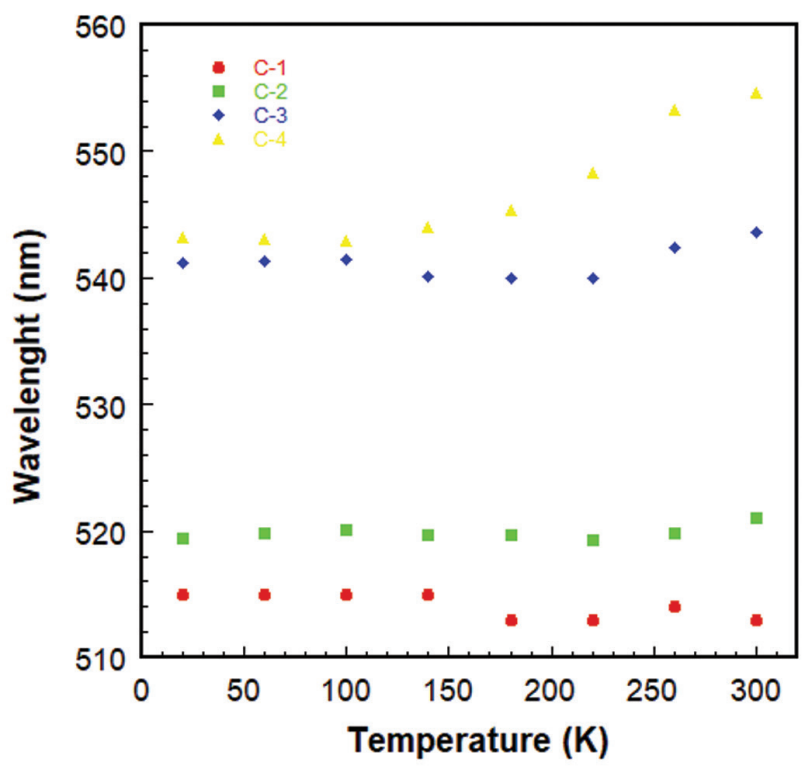

Figure 3 Temperature dependent peak positions of PL spectra, as observed. The change of integrated intensity within a temperature range of $20-300 \mathrm{~K}$ for $\mathbf{C}-\mathbf{3}$ is approximately three times, while for $\mathbf{C}-\mathbf{4}$ it is about 2.3 times. This is probably due to the difference in stereoelectronic effect of compounds attached to the alpha and beta positions.

Figure 5 shows the excitation power density dependent normalized integrated intensities for all samples. As seen from the figure integrated intensity increases with excitation power density as expected. At high excitation density, a small degree of saturation is realized.

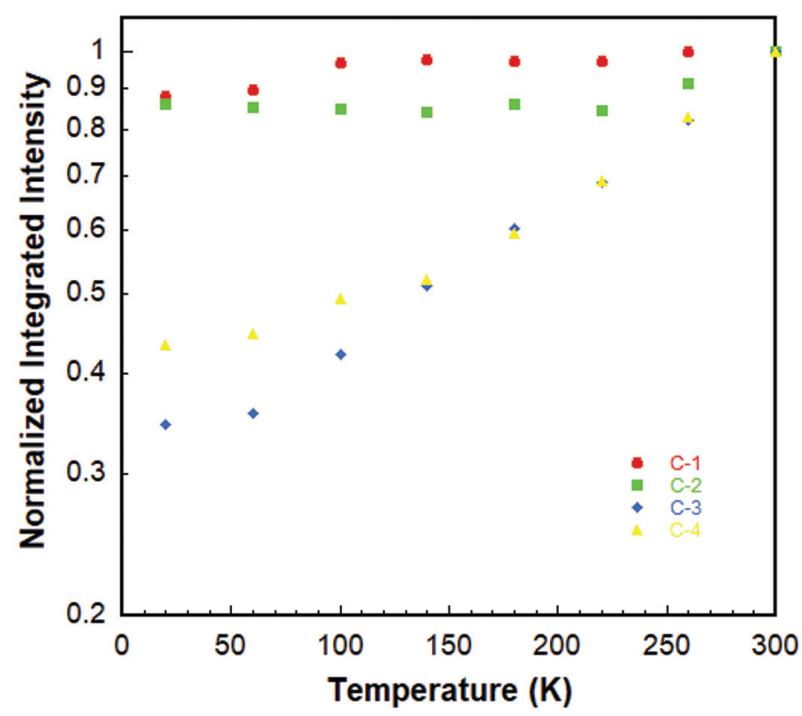

Figure 4 The normalized integrated intensity versus temperature for all samples

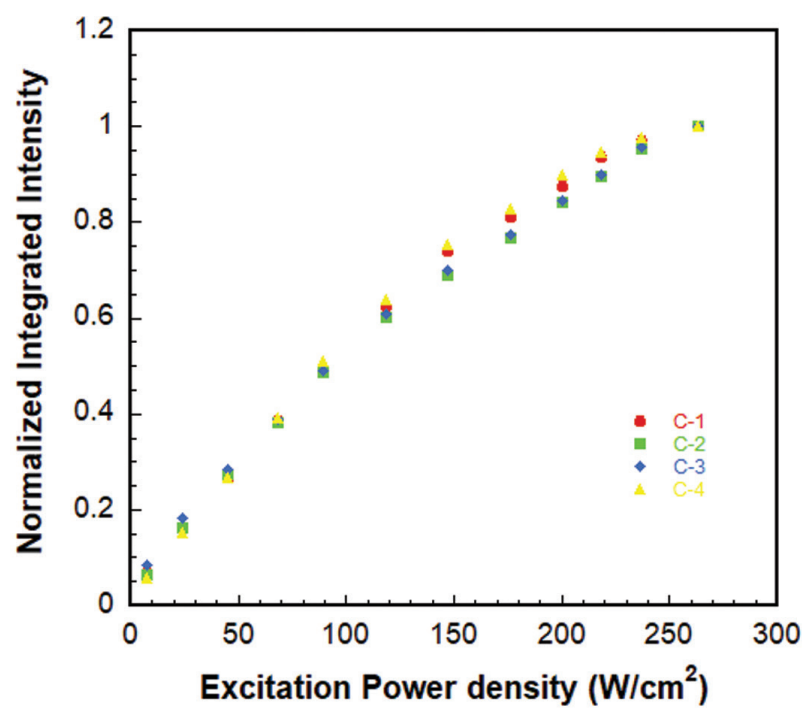

Figure 5 The normalized integrated intensity versus excitation density for all samples 


\section{Conclusions}

In this study, some original bipod carbazole derivatives named as C-1, C-2, C-3 and C-4 were successfully synthesized using a Suzuki-Miyaura Cross Coupling reaction between 1,2-bis-3,6-dibromo depot carbazole and aromatic boronic acids. The compounds $\mathbf{C}-\mathbf{3}$ and $\mathbf{C}-\mathbf{4}$ were obtained by substituting the $\alpha$ - and $\beta$-naphthalene on 3- and 6- positions of carbazole for the first time. They were characterized by FT-IR, ${ }^{1} \mathrm{H}$-NMR, ${ }^{13} \mathrm{C}$-NMR, LC-MS and elemental analysis methods, confirming their formations. The optical characterization was performed by using UV visible spectroscopy and temperature and excitation power density dependent PL measurements. Compared with a reference carbazole host material, two broad peaks were resolved by applying Gaussian fitting to PL spectra in the wavelength range of 510-520 (greenish) and 620-630 (reddish) for all samples. This demonstrates an efficient charge transfer to $\pi$-conjugated systems, dependent on associated functional groups. These newly synthesized bipod carbazole derivatives could be explored for organic light emitting diodes as an active emissive or hole transport layer. The emission wavelengths can be shifted as desired by optimizing or changing the functional groups. In order to test their use in such devices, they must be produced with appropriate layer and contact configurations in a device design.

Conflict of interest: The authors state no competing financial interests.

Funding source: This study was supported by Balıkesir University Projects Unit; project no: BAP.2013/36 and 2017/181.

Acknowledgements: In this study, Baki Çiçek and Merve Çağlı designed the study and performed syntheses and characterizations. Remziye Tülek and Ali Teke performed PL experiments. All authors evaluated the results and prepared the manuscript. This work was supported by Balikesir University Research Grant Numbers: 2013/36 and 2018/148. We are also very grateful to the reviewers for valuable comments that improved our manuscript.

Supplementary material: All FT-IR, ${ }^{1} \mathrm{H}-\mathrm{NMR},{ }^{13} \mathrm{C}-\mathrm{NMR}$, LC-MS spectrums (Figures 1-5) for syntheses (C-1)-(C-4) are given in Supportive/Supplementary material.

\section{References}

[1] Müllen K, Scherf U. Organic Light Emitting Devices: Synthesis, Properties and Applications; Wiley-VCH: Weinheim, 2006, pp. 215-316.

[2] Mazetyte D, Krucaite G, Grazulevicius JV, Chiang Cl, Yang FC, Jou $\mathrm{JH}$, et al. Carbazole- and phenylindole-based new host materials for phosphorescent organic light emitting diodes. Opt Mater. 2013;35(3):604-8.

[3] Grigalevicius S, Tavgeniene D, Krucaite G, Blazevicius D, Griniene R, Lai YN, et al. Efficient blue and green phosphorescent OLEDs with host material containing electronically isolated carbazolyl fragments. Opt Mater. 2018;79:446-9.

[4] Sun SS, Sariciftci NS. Organic Photovoltaics: Mechanisms, Materials, and Devices. 1st Editio. Boca Raton (Florida): CRC Press; 2005.

[5] Mas-Torrent M, Rovira C. Tetrathiafulvalene derivatives for organic field effect transistors. J Mater Chem. 2006;16:433-6.

[6] Suh SC, Shim SC. Synthesis and properties of a novel polyazomethine, the polymer with high photoconductivity and second-order optical nonlinearity. Synth Met. 2000;114(1): 91-5.

[7] Ma H, Jen AK, Dalton LR. Polymer-based optical waveguides: Materials, processing, and devices. Adv Mater. 2002;14(19):1339-65.

[8] Kanis DR, Ratner MA, Marks TJ. Design and Construction of Molecular Assemblies with Large Second-Order Optical Nonlinearities. Quantum Chemical Aspects. Chem Rev. 1994;94(1): 195-242.

[9] Jeon BJ, Jin Jl, Cha SW, Jeong MY, Lim TK. Synthesis and 2nd order nonlinear optical properties of soluble polyimides bearing nitroazobenzene type chromophore pendants attached in side-on mode.J Mater Chem 2002;12:546-52.

[10] Jiang H, Sun J, Zhang J. A Review on synthesis of carbazolebased chromophores as organic light-emitting materials. Curr Org Chem. 2012;16(17):2014-25.

[11] Liger F, Popowycz F, Besson T, Picot L, Galmarini CM, Joseph B. Synthesis and antiproliferative activity of clausine E, mukonine, and koenoline bioisosteres. Bioorg Med Chem. 2007;15(16):5615-9.

[12] Choi TA, Czerwonka R, Fröhner W, Krahl MP, Reddy KR, Franzblau $\mathrm{SG}$, et al. Synthesis and activity of carbazole derivatives against Mycobacterium tuberculosis. ChemMedChem. 2006;1(8): 812-5.

[13] Ushio-Fukai M, Hossain CF, Perry BN, Liu A, Klein E, Nagle DG, et al. Carbazole is a naturally occurring inhibitor of angiogenesis and inflammation isolated from antipsoriatic coal tar. J Invest Dermatol. 2006;126(6):1396-402.

[14] Sakano K-I. Ishimaru K, Nakamura S. New antibiotics, carbazomycins A and B. I. Fermentation, extraction, purification and 
physico-chemical and biological properties. J Antibiot (Tokyo). 1980;33(7):683-9.

[15] Bergman J, Pelcman B. Synthesis of carbazole alkaloids. Pure \& Appl. Chem. 1990;62(10):1967-76.

[16] Archer S, Ross BS, Pica-Mattoccia L, Cioli D. Synthesis and biological properties of some GH-pyrido[ 4,3-b ]carbazoles. J Med Chem. 1987;30:1204-10.

[17] Kirsch G. Heterocyclic analogues of carbazole alkaloids. Curr Org Chem. 2001;5(5):507-18.

[18] Haider N. Diazine analogues of the pyridocarbazole alkaloids. Curr Org Chem. 2006;10(3):363-75.

[19] Forrest SR. The path to ubiquitous and low-cost organic electronic appliances on plastic. Nature. 2004;428:911-8.

[20] Strohriegl P, Grazulevicius JV. Charge-transporting molecular glasses. Adv Mater. 2002;14(20):1439-52.

[21] Vandana T, Ramkumar V, Kannan P. Synthesis and fluorescent properties of poly(arylpyrazoline)'s for organic-electronics. Opt Mater. 2016;58:514-23.

[22] Grigalevicius S, Buika G, Grazulevicius JV, Gaidelis V, Jankauskas V, Montrimas E. 3,6-Di(diphenylamino)-9-alkylcarbazoles: novel hole-transporting molecular glasses. Synth Met. 2001;122(2):311-4.

[23] Chen JP, Tanabe H, Li XC, Thoms T, Okamura Y, Ueno K. Novel organic hole transport material with very high Tg for light-emitting diodes. Synth Met. 2003;132(2):173-6.

[24] Zhang Q, Chen J, Cheng Y, Wang L, Ma D, Jing X, et al. Novel hole-transporting materials based on 1,4-bis(carbazolyl) benzene for organic light-emitting devices. J Mater Chem. 2004;4:895-900.

[25] Velasco D, Jankauskas V, Stumbraite J, Grazulevicius JV, Getautis V. Indolo[3,2-b]carbazole derivatives as hole transporting materials for electrophotography. Synth Met. 2009;159(7-8):654-8.

[26] Kirkus M, Simokaitiene J, Grazulevicius JV, Jankauskas V. Phenyl-, carbazolyl- and fluorenyl-substituted derivatives of indolo[3,2-b]carbazole as hole-transporting glass forming materials. Synth Met. 2010;160(7-8):750-5.

[27] Lengvinaite S, Grazulevicius JV, Grigalevicius S, Gu R, Dehaen W, Jankauskas V, et al. Indolo[3,2-b]carbazole-based functional derivatives as materials for light emitting diodes. Dyes Pigments. 2010;85(3):183-8.

[28] Simokaitiene J, Grigalevicius S, Grazulevicius JV, Jankauskas V, Sidaravicius J. Hole-transporting carbazole-based imines. Mol Cryst Liq Cryst (Phila Pa). 2011(1);536:192-9.

[29] Wang Z, Zhang H, Wen X, Yu T, Fan D, Zhao Y. Synthesis, crystal structure and photoluminescence of phosphorescent copper (I) complexes containing hole-transporting carbazolyl group. Inorg Chim Acta. 2011;383:78-82.

[30] Zhao HP, Tao XT, Wang P, Ren Y, Yang JX, Yan YX, et al. Effect of substituents on the properties of indolo[3,2-b]carbazole-based hole-transporting materials. Org Electron. 2007;8(6):673-82.
[31] Jeon YP, Kim KS, Lee KK, Moon IK, Choo DC, Lee JY, et al. Blue phosphorescent organic light-emitting devices based on carbazole/thioxanthene-S,S-dioxide with a high glass transition temperature. J Mater Chem C Mater Opt Electron Devices. 2015;3:6192-9.

[32] Zhan Y, Xu Y, Yang P, Zhang H, Li Y, Liu J. Carbazole-based salicylaldimine difluoroboron complex with crystallization-induced emission enhancement and reversible piezofluorochromism characteristics. Tetrahedron Lett. 2016;57(48):5385-9.

[33] Lai H, Hong J, Liu P, Yuan C, Li Y, Fang Q. Multi-carbazole derivatives: new dyes for highly efficient dye-sensitized solar cells. RSC Advances. 2012;2:2427-32.

[34] SlodekA, Zych D, Maroń A, Malecki JG, Golba S, Szafraniec-Gorol G, et al. Does the length matter? - Synthesis, photophysical, and theoretical study of novel quinolines based on carbazoles with different length of alkyl chain. Dyes Pigments. 2019;160:604-13.

[35] Çiçek B, Çalışır Ü, Tavaslı M, Tülek R, Teke A. Synthesis and optical characterization of novel carbazole Schiff bases. J Mol Struct. 2018;1153:42-7.

[36] Yamashita M, Horiguchi H, Hirano K, Satoh T, Miura M. Fused ring construction around pyrrole, indole, and related compounds via palladium-catalyzed oxidative coupling with alkynes. J Org Chem. 2009;74(19):7481-8.

[37] Tsai MH, Lin HW, Su HC, Ke TH, Wu CC, Fang FC, et al. Highly efficient organic blue electrophosphorescent devices based on 3,6-Bis(triphenylsilyl)carbazole as the host material. Adv Mater. 2006;18(9):1216-20.

[38] Tsai MH, Ke TH, Lin HW, Wu CC, Chiu SF, Fang FC, et al. Triphenylsilyl- and trityl-substituted carbazole-based host materials for blue electrophosphorescence. ACS Appl Mater Interfaces. 2009;1(3):567-74.

[39] Qian Y. 3,6-Disubstituted carbazole chromophores containing thiazole and benzothiazole units: Synthesis, characterization and first-order hyperpolarizabilities. Dyes Pigments. 2008;76(1):277-81.

[40] Qiu Y, Duan L, Jiang W, Qiao J, Wang L, Zhang D, et al. Hightriplet-energy tri-carbazole derivatives as host materials for efficient solution-processed blue phosphorescent devices. J Mater Chem. 2011;21:4918-26.

[41] Berton N, Fabre-Francke I, Bourrat D, Chandezon F, Sadki S. Poly(bisthiophene-carbazole-fullerene) double-cable polymer as new donor-acceptor material: preparation and electrochemical and spectroscopic characterization. J Phys Chem B. 2009;113(43):14087-93.

[42] Aydin A, Kaya I. Synthesis and characterization of yellow and green light emitting novel polymers containing carbazole and electroactive moieties. Electrochim Acta. 2012;65:104-14.

[43] Ostrauskaite J, Voska V, Grazulevicius JV. Synthesis and properties of glass-forming hydrazones II [1]. Hydrazones containing bicarbazolyl units. Monatsh Chem. 2002;133:599-607. 
[44] Agarwal N, Nayak PK, Ali F, Patankar MP, Narasimhan KL, Periasamy N. Tuning of HOMO levels of carbazole derivatives: new molecules for blue OLED. Synth Met. 2011;161(5-6): 466-73.

[45] Ben-Yahia A, Naas M, Brahmi N El, Kazzouli S El, Majoral J-P, Guillaumet EME and G. Microwave-assisted Suzuki-Miyaura cross-coupling of free (NH) 3-Bromoindazoles. Curr Org Chem. 2013;17(3):304-9.

[46] Hassine A, Bouhrara M, Sebti S, Solhy A, Mahfouz R, Luart D, et al. Natural Phosphate-supported Palladium: A Highly Efficient and Recyclable Catalyst for the Suzuki-Miyaura Coupling Under Microwave Irradiation. Curr Org Chem. 2014;18(24):3141-8.
[47] Çiçek B. Synthesis of Tetra-Aza Coronands and Determination of Complexity Capabilities by Potentiometric, Conductometric and Liquid-Liquid Extraction Methods [dissertation]. [Balıkesir]: Balıkesir University; 2002, pp.59-66.

[48] de Meijere A, Diederich F. Metal-Catalyzed Cross-Coupling Reactions; Wiley-VCH: Weinheim, 2008, pp. 41-760.

[49] Grigoras M, Antonoaia NC. Synthesis and characterization of some carbazole-based imine polymers. Eur Polym J. 2005;41(5):1079-89.

[50] Slodek A, Zych D, Maroń A, Golba S, Schab-Balcerzak E, Janeczek $\mathrm{H}$, et al. Fluorene vs carbazole substituent at quinoline core toward organic electronics. Dye Pigment 2019;166:98-106. 